\title{
Research Paper: Relationship of Perception of Organizational Politics With Turnover Intentions, Job Performance, and Organization Citizenship Behavior: Emphasis on the Mediating Role of Organizational Justice
}

\author{
*Zeynab Seyed Nazari ${ }^{1}$, Mohammad Hassani ${ }^{1}$, Ali Reza Ghaleei ${ }^{1}$, Mahdi Kazemzade Beytali ${ }^{1}$
}

1. Department of Educational Administration, Faculty of Literature and Humanities, University of Urmia, Urmia, Iran. zational Politics With Turnover Intentions, Job Performance, and Organization Citizenship Behavior: Test the Mediating Role of Organizational Justice (Persian)]. Journal of Rehabilitation. 2017; 17(4):338-349. http://dx.doi.org/ 10.21859/jrehab-1704338

Received: 8 Aug. 2016 Accepted: 27 Oct. 2016

Keywords: Organizational justice, Organizational politics, Turnover intentions, Job performance, Organizational citizenship behavior

\section{A B STRACT}

Objective Political behavior in organizations is influenced by the differences in perceptions and attitudes of the staff, nature of the action, or people's perception of reality. Such behavior stems from the perception and reaction to self-interest. Different studies have showed that this behavior is an inevitable part of any human activity. Staff when asked about political behavior in the workplace, Often it related to serve their behaviors and to consider as a phenomenon dirty that the personal goals at the expense of other researchers. Such behavior may be harmful to the objectives of the organization and can be considered as a threat to the organizational effectiveness and organizational performance. If employees feel good he has deceived organizational policies, Possible show negative reactions such as annoyance, frustration, anxiety and movement. Most researchers have argued the perception of policy of stressful and harmful and potential negative effects on a wide range of business and personal consequences. Although policies may be both positive as well as negative perceptions, due to the strength of contagion in the organization venice extremely negative consequences resulting from negative policies The present study was conducted to survey the relationship of perception of organizational politics with turnover intentions, job performance, and organization citizenship behavior considering the mediating role of organizational justice.

Methods \& Materials This descriptive-analytic study consisted of a sample of 200 employees of the welfare organization and its assemblies in West Azarbaijan. Data were collected using standard questionnaires of Kacmar and Carlson's Perception of Organizational Politics, Niehoff and Moorman's Organizational Justice, Miller, Katerberg and Hulin's Turnover Intentions, Williams and Anderson's Job Performance, and Podsakoff et al.'s Organization Citizenship Behavior. Structural Equation Modeling was applied to evaluate the relationships between latent and measured variables in a conceptual model. Results The results showed that the politic variables had a negative significant correlation with organizational justice $(r=-0.37)$, job performance $(r=-0.14)$, and organization citizenship behavior $(r=-0.27)$. A significant positive correlation was observed between politic variables and turnover $(r=-0.45)$. A significant positive correlation was also observed between justice and job performance and organizational citizenship behavior $(r=0 / 12, r=0.11, p<0.01)$, whereas a negative significant correlation was evident with turnover intentions. The rate of pairwise correlation fluctuated from 0.11 to 0.45 .

Conclusion We concluded that any increase in the perception of organizational politics is accompanied by an increase in the staffs' turnover intention and a decrease in justice, job performance, and organizational citizenship behavior.

\section{* Corresponding Author: \\ Zeynab Seyed Nazari, MSc.}

Address: Department of Educational Administration, Faculty of Literature and Humanities, University of Urmia, Urmia, Iran.

Tel: +98 (937) 9819381

E-Mail: seyednazari@gmail.com 


\title{
رابطه بين ادراى از فضاى سياسى سازمان با تمايل به ترك شغلى، عملكرد شغلى و رفتار شهروندى سازمانى: أزمون ميانجى عدالت سازئ سارئى سازمان
}

\author{
"زينب سيدنظرى'، محمد حسنى'، علىرضا قلعهاى'، مهدى كاظمزادهبيطالى' \\ 1- اكروه مديريت أموزشي، دانشكده ادبيات وعلوم انسانى، دانشكاه اروميه، اروميه، ايران.
}

\begin{abstract}
حكبد

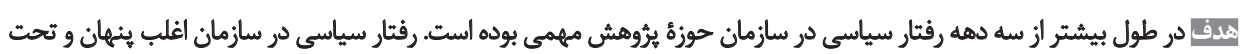

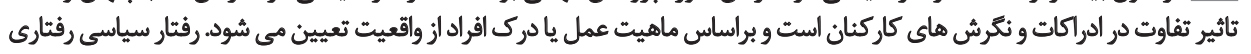

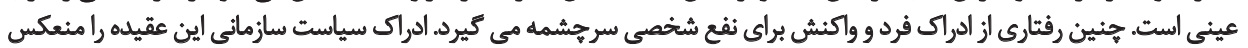

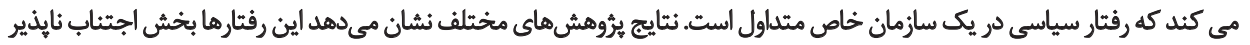

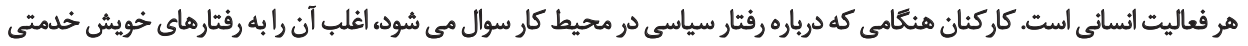

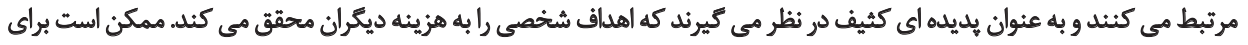

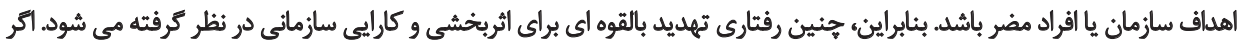

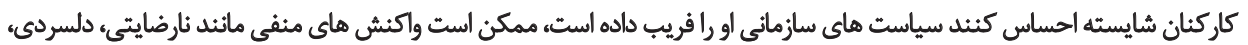

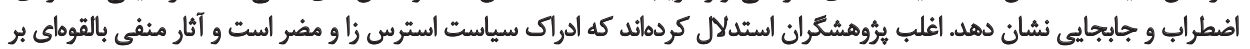

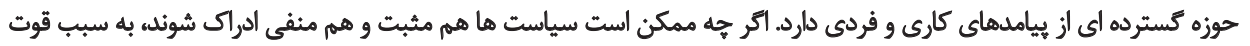

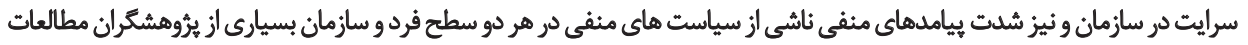

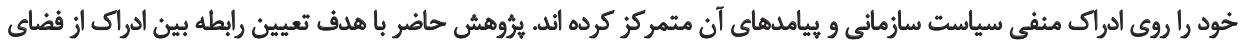

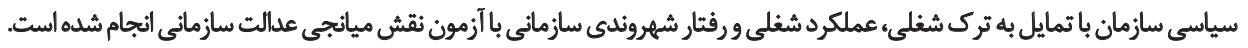

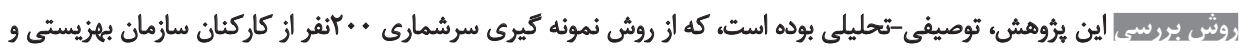

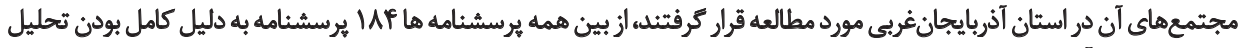

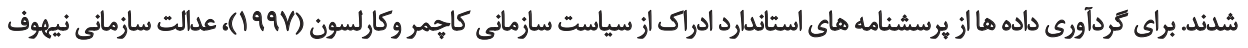

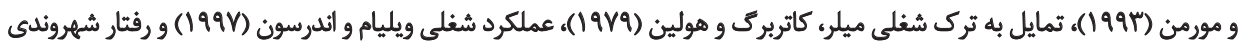

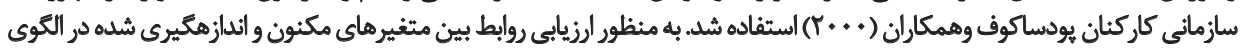

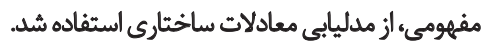

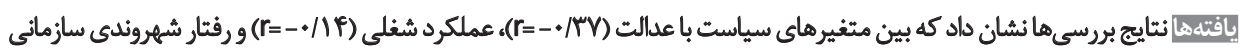

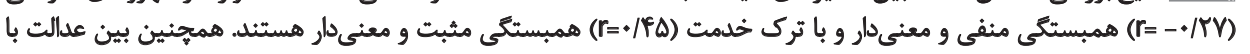

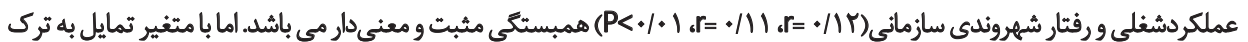

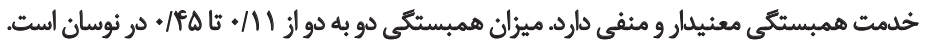

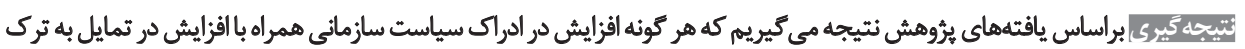

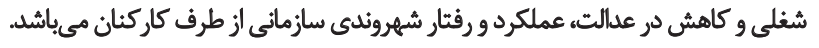

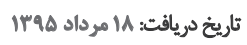

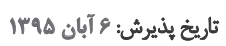

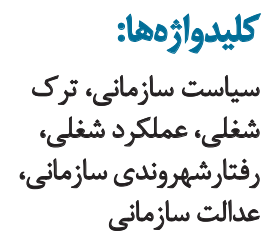

عدالت سازماني

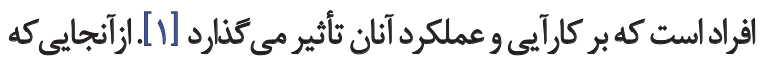

مقدمه

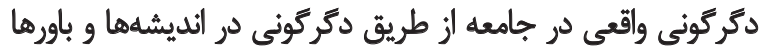

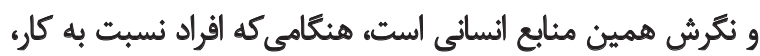

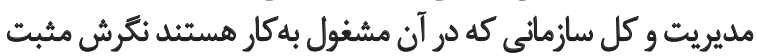

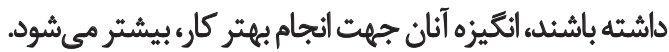

در شرايط متغير كنونى، سازمانها براى دستيابى به كارآيى و ونائي

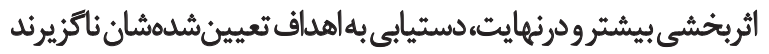

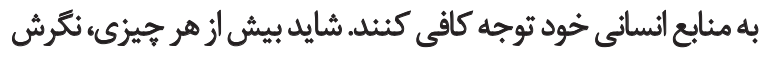

- 
عدالت مراودهاي به ادراى افراد از كيفيت روابط درونفردى در إراني

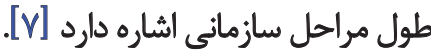
ازطرفديكر، ادراك سياست سازمانى بهعنوان ادراك افراد ازئ

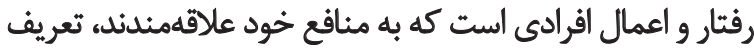

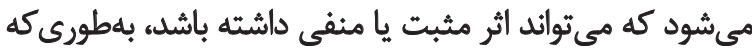

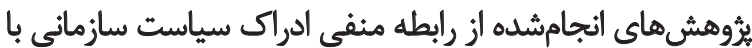

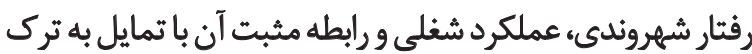
شغلى حكايت دارد.

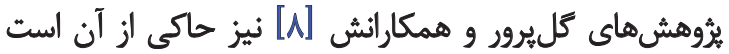

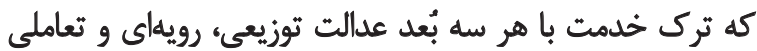

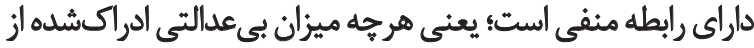

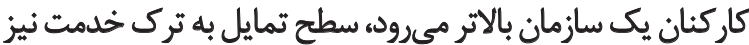

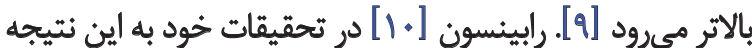

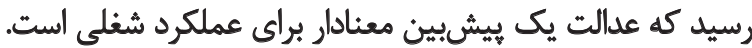

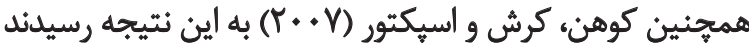

كه عملكرد شغلى از اثرات عدالت سازمانى بهشمار مي آيد [11]. بلنظر آلير [IT] عواملى مانئد عدالت با رفتار شهروندى

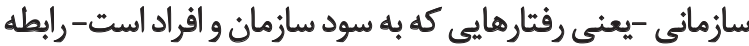

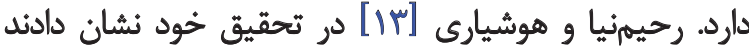

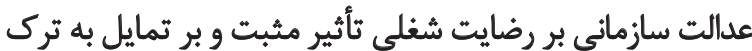

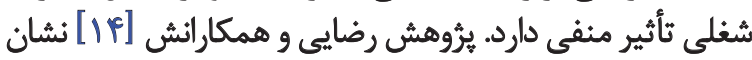

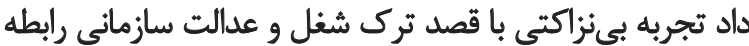

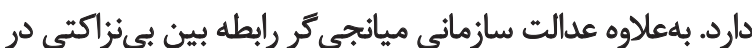
محيط كار و قصد ترك شغل است.

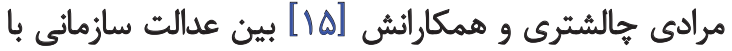

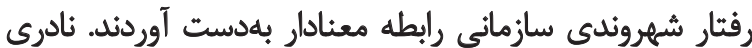

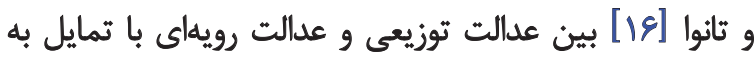

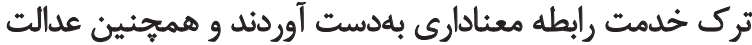

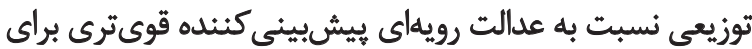

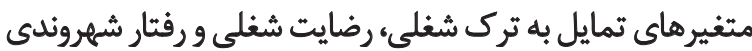

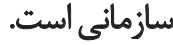

همجنين عملكرد شغلى، حاصل انتظارات مشخص و معيني

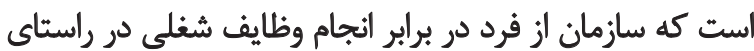

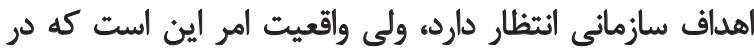

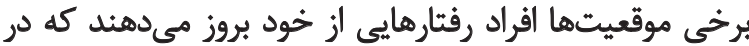

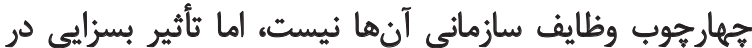

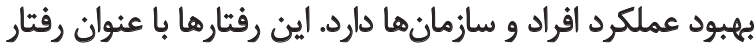

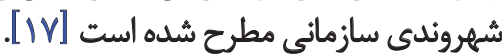
رايجترين تعريفى كه درباره اين موضوع مقبوليت ييدا كرده

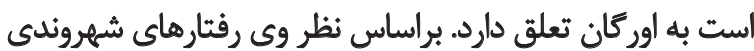

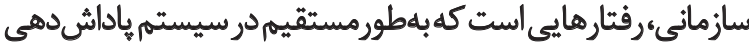

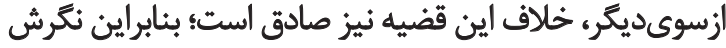

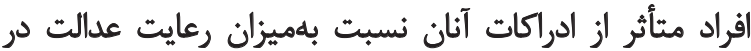

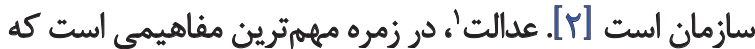

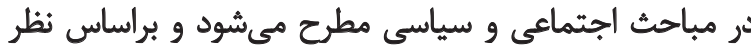

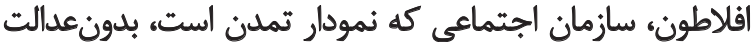

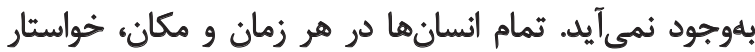

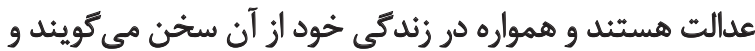

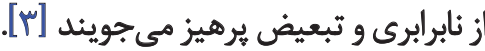
درواقع، سازمانهاى امروزى مينياتورى از جامعه محسوب

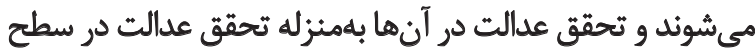

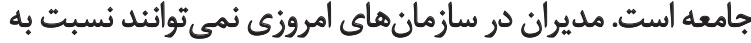

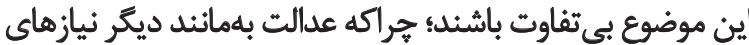

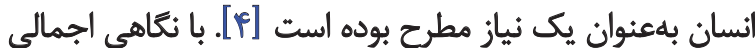

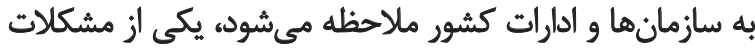

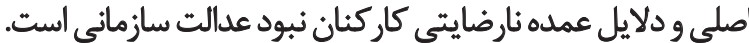

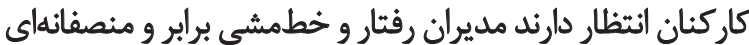

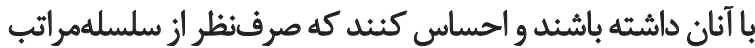

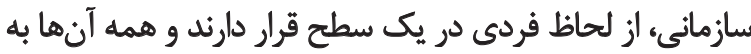
يك اندازه بالهميث شمرده مي لمشوند. از مصاديق بارز نابرابرى در سازمان آن است كه افراد احساس

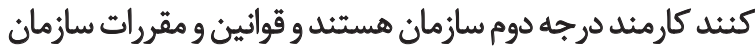

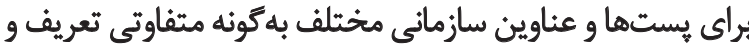

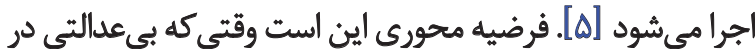

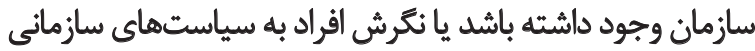
منفى باشد، بلطور تضعيف كنندهاي سطح رضايت، عملكرد و ورفتار

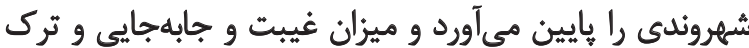

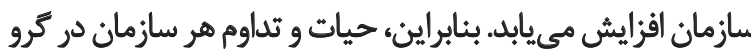

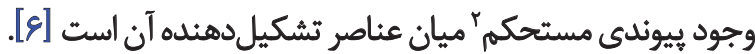

در ادبيات سازمان و مديريت، واره عدالت ابتداتوسط گرينبرك" (19AV)

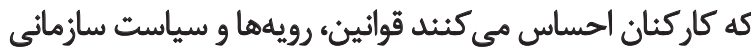

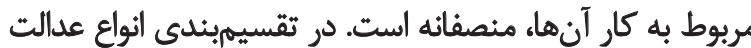

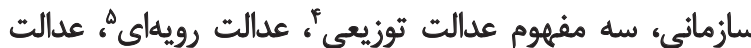

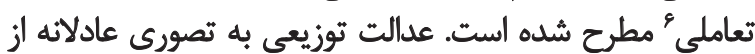

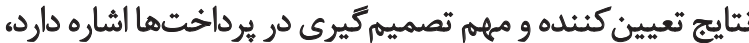

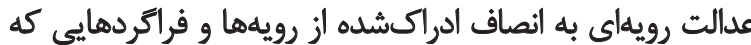

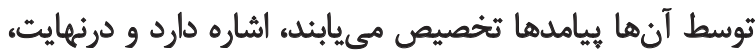

1. Justice

2. Astrong link

3. Greenberg

4. Distributive justice

5. Procedural justice

6. Interactional justice 


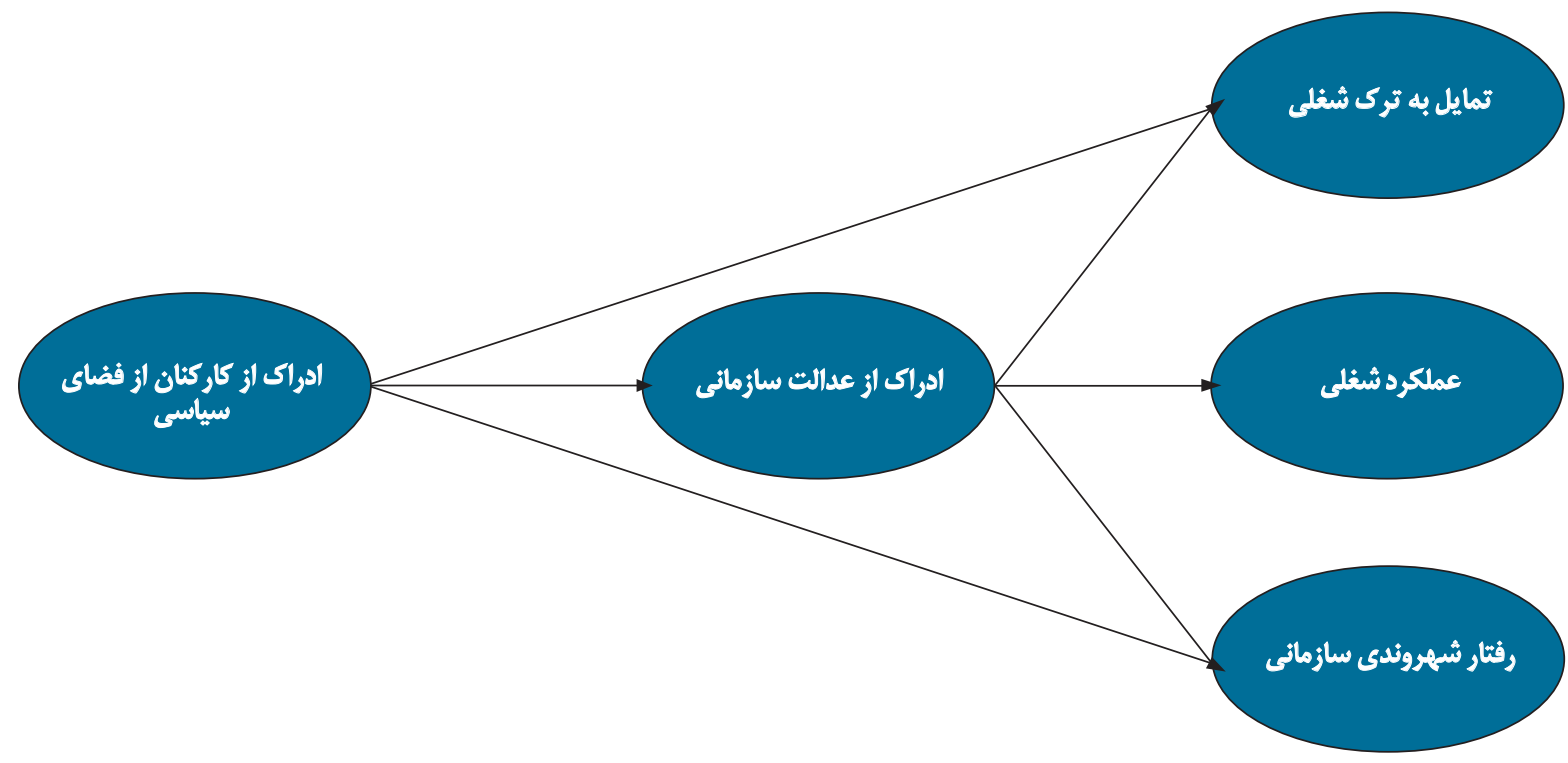

توانبخننى

تصوير ا. مدل مفهومي ثبروهش.

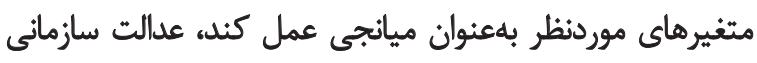

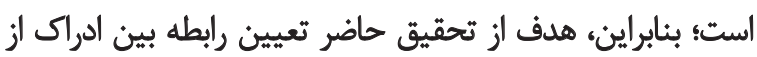

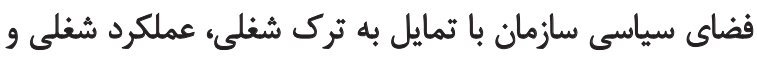

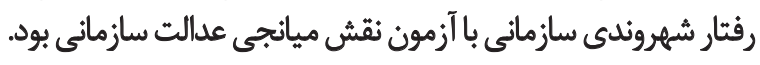

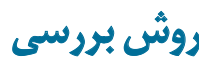

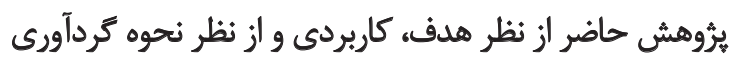

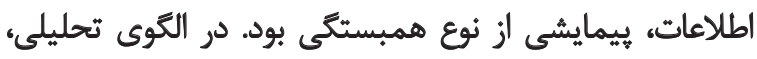

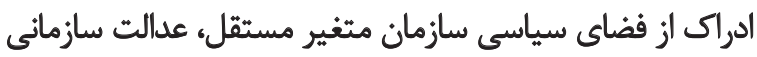

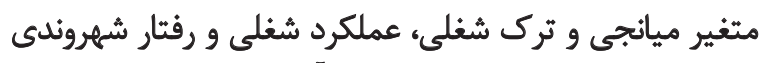

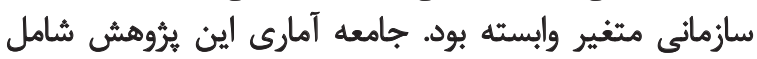

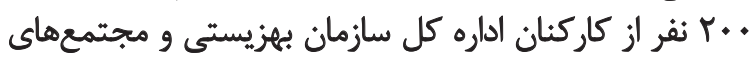

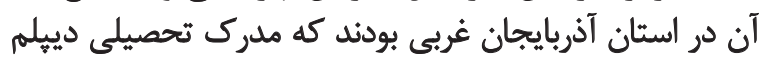

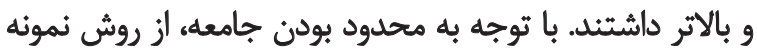

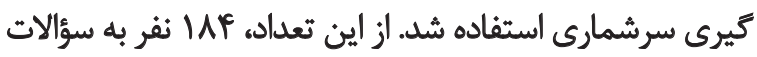

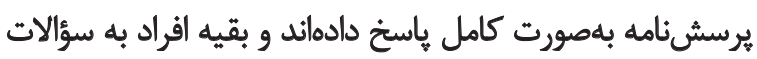

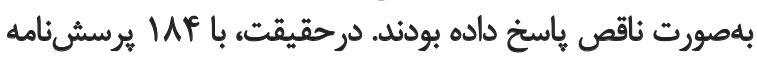

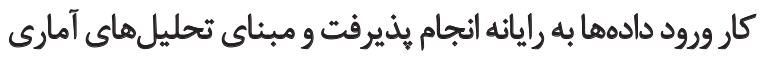

$$
\text { و مديريتى قرار كرفت. }
$$

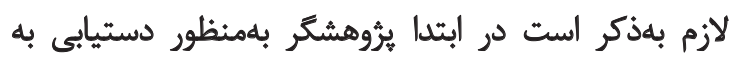

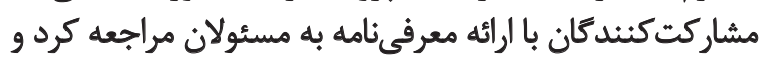

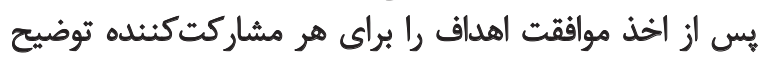

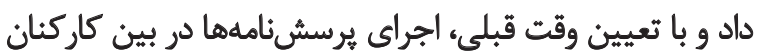

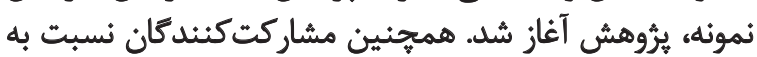

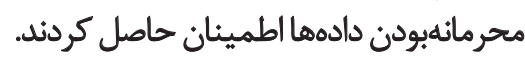

رسمى سازمان ذكر نشده است و بيشتر بهدست فراموشى سيرده

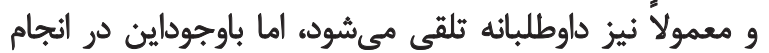

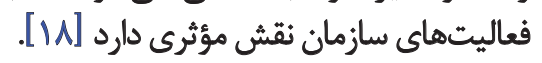

رفتار شهروندى در سازمانى مائند سازمان بهزيستى از جايتاه

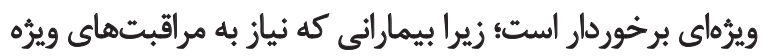

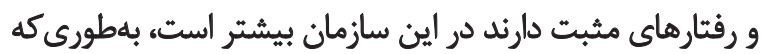

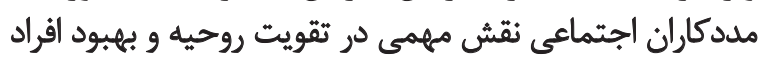

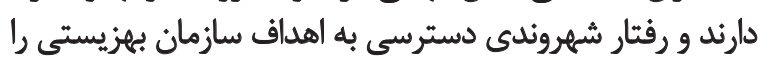

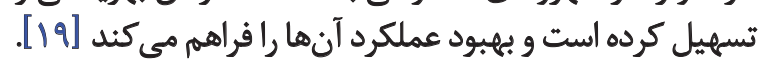

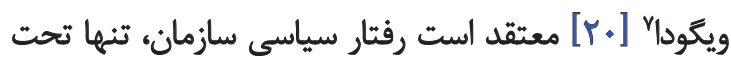

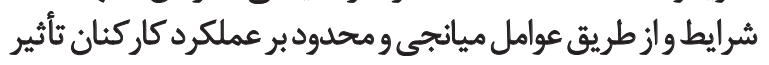

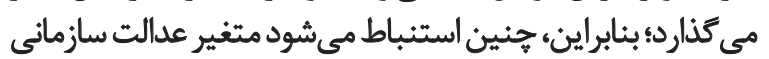

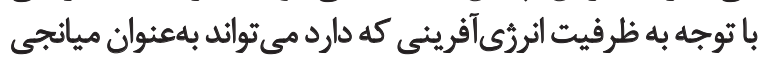

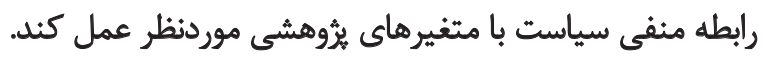

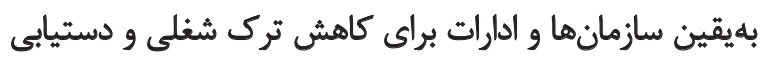

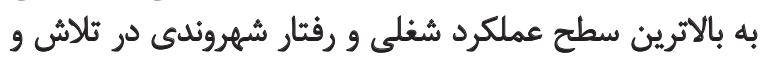

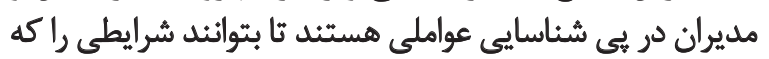

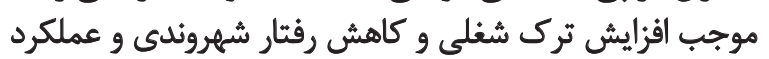

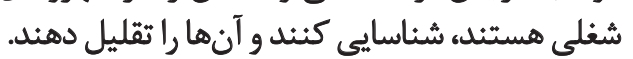

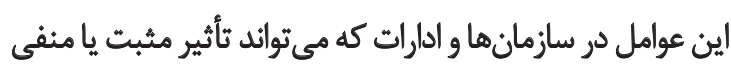

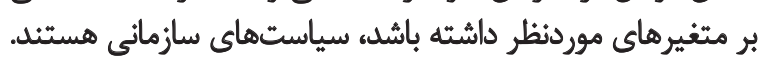

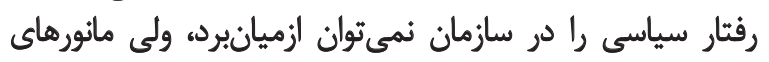

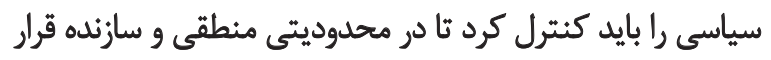

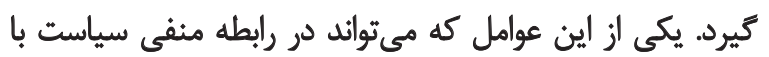


در ثيروهش حاضر براي ارزيابي هايايى از آلفاي كرونباخ استفاده

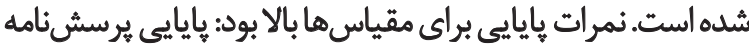

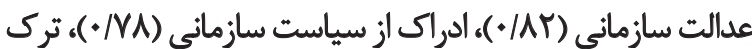

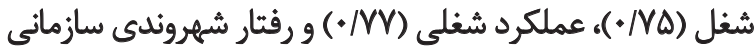

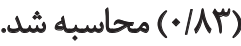

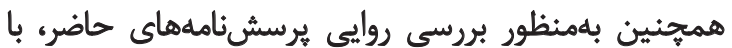

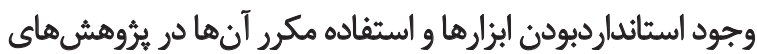

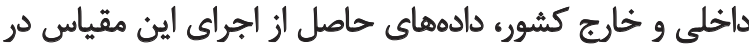

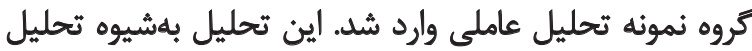

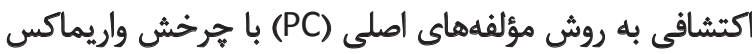

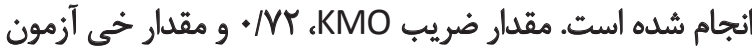

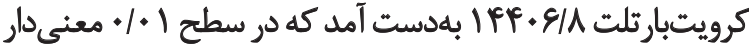

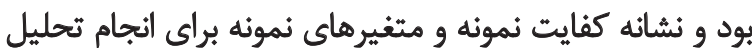

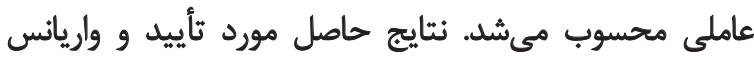
تجميعى حدود /VA • بهدست آمده است.

در بُروهش حاضر از روشهاى آمار توصيفى و آمار استنباطى إسى

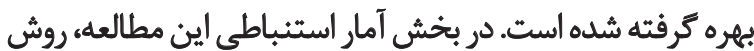

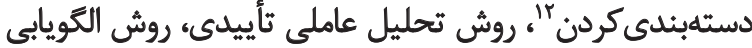

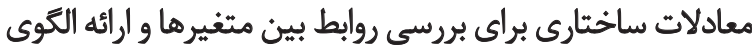

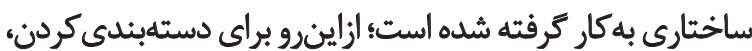

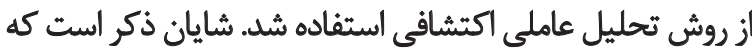

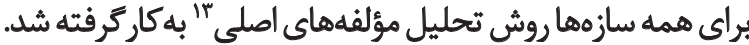

\section{يافتهها}

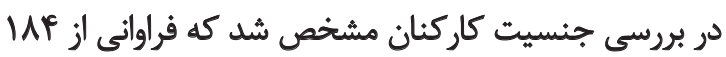

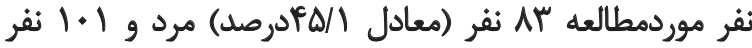

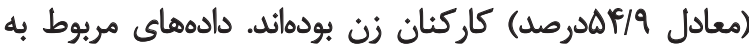

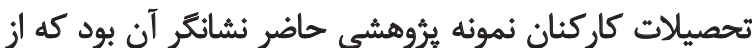

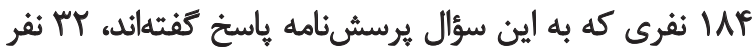

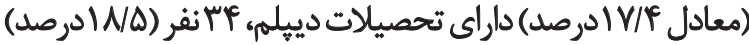

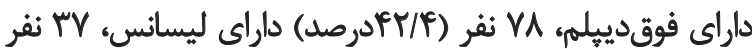

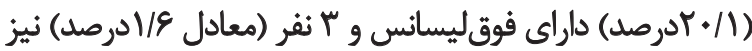
داراى تحصيلات دكترى بودند.

همجينين دادههاي مربوط به سابقه كار كاركنان نمونه يروهش

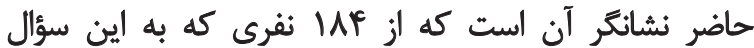

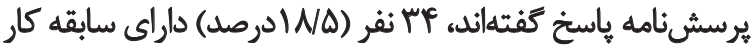

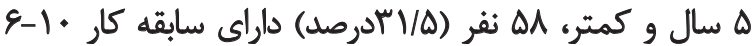

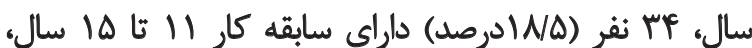

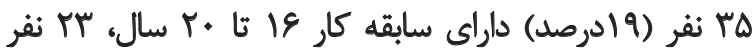

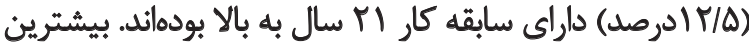

12. Parceling

13. Principal component analysis

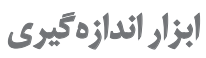

در اين بروهش، براي جمعآورى اطلاعات از ينج يرسشنامه

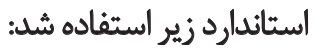

• يرسشنامه عدالت سازمانى: اين متغير با استفاده از مقياس

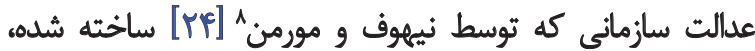

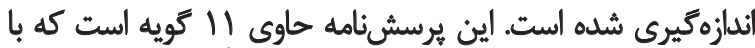

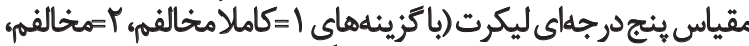

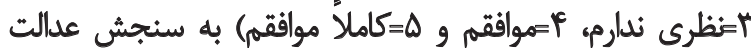

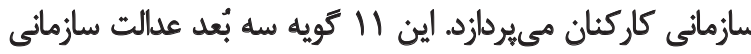

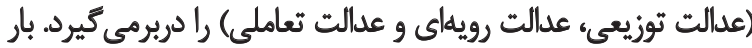

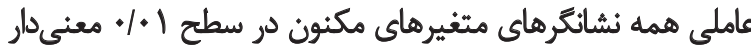

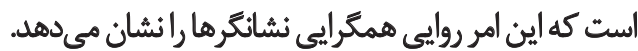

•برسش بامه ادراك از سياست سازمانى: سياست سازمانى با استفاده از مقياس ادراكات سياست سازماني (POPS) كه توساسي

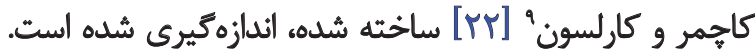

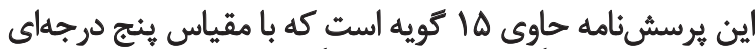

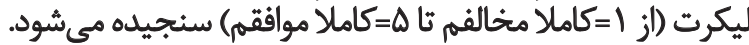
• يرسش إنامه تمايل به ترك شغلى : تمايل به ترك شغلى

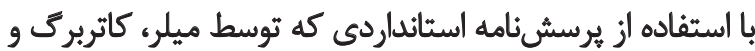

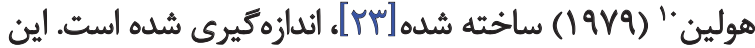

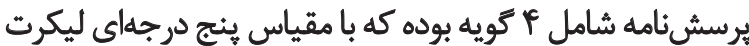

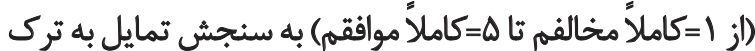

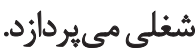

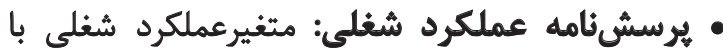

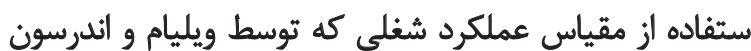

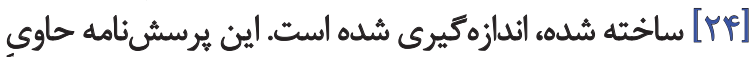

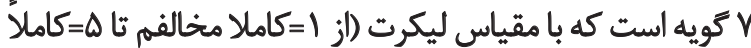

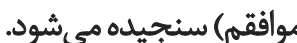
• يرسش كامنامه رفتار شهروندى سازمانى: رفتار شهروندى

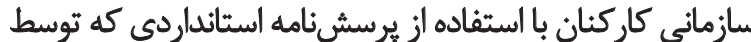

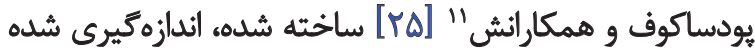

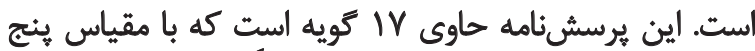

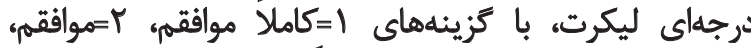

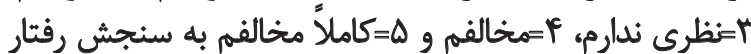

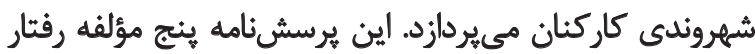

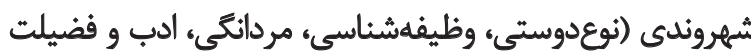

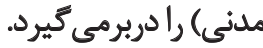

8. Niehoff and Moorman

9. Kacmar and Carlson

10. Miller, Katerberg and Hulin

11. Podsakoff, Mackenzie, BethPain and Bachrach 


\begin{tabular}{|c|c|c|c|c|}
\hline \multicolumn{5}{|c|}{ جدول (. ماتريس كواريائس متغيرهاي مكئون. } \\
\hline رفتار شهروثدى & عملكرد & ترى خدمت & عدالت & | متغيرها \\
\hline$-+/ R V^{* *}$ & $-* / / N$ &.$/ P D^{* *}$ &.$- / 4 r e *$ & سياست \\
\hline.$M *$ &.$/ r^{*}$ & $-* / r^{*}$ & & ع عالت \\
\hline$\%$ & $-\cdot / 1 r^{*}$ & & & ترك خلمت \\
\hline \multirow[t]{2}{*}{./ץイ** } & & & & عملكرد \\
\hline & & & & رقفتار شُهروندى \\
\hline & & & & $\begin{array}{c}\mathrm{P}<* / \cdot 1^{* *} \\
\mathrm{P}<* / \cdot \Delta^{*}\end{array}$ \\
\hline
\end{tabular}

\begin{tabular}{|c|c|c|c|c|c|c|c|}
\hline CFI & NNFI & RMSEA & IFI & GFI & df & $X^{r}$ & شاخصها \\
\hline .19 & $\cdot / N$ & 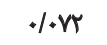 & .19. &.$/ 19$ & Meg & $1 .+A W$ & مقدار نهايي \\
\hline
\end{tabular}

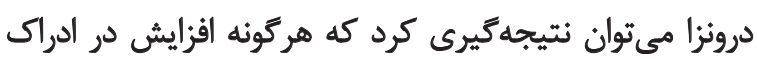

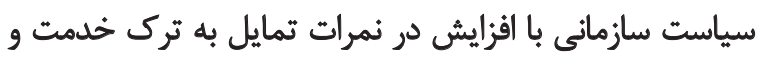

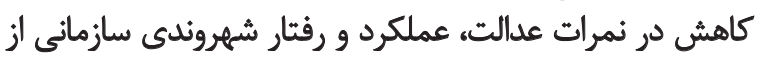

$$
\text { طرف كاركنان همراه است. }
$$

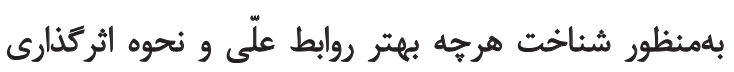

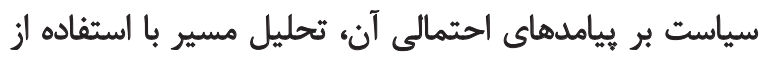

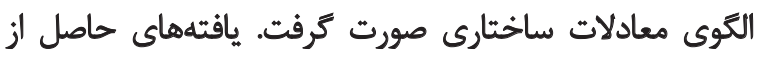

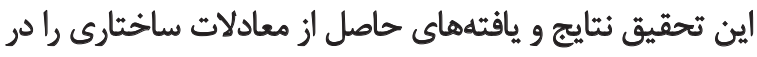

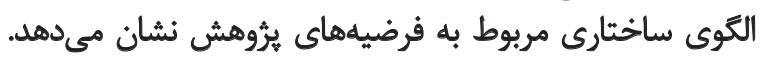

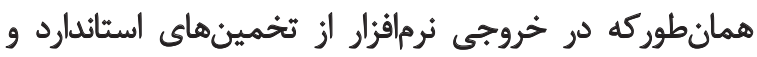

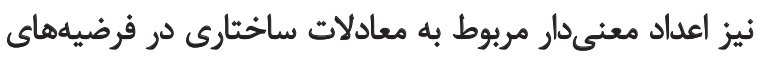

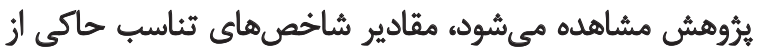

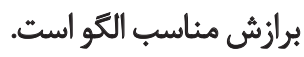

فراوانى در سابقه كار ع تا ـ ا سال ديده مي مشود.

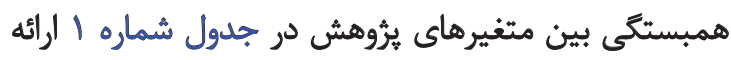

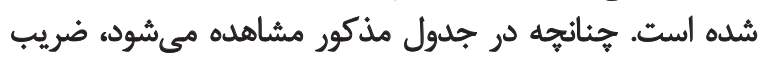

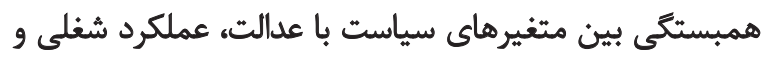

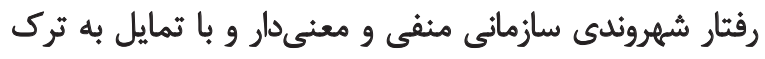

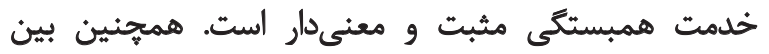

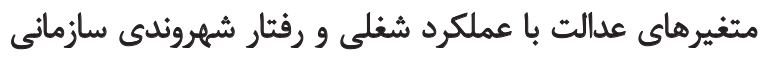

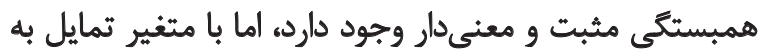
ترك خدمت همبستخى معنى دار و منفى دارد.

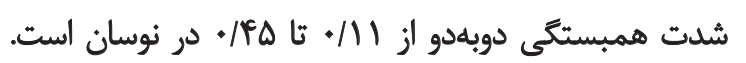

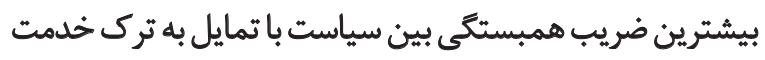

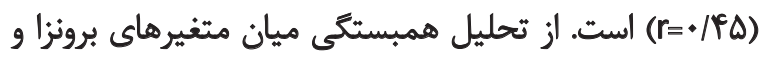

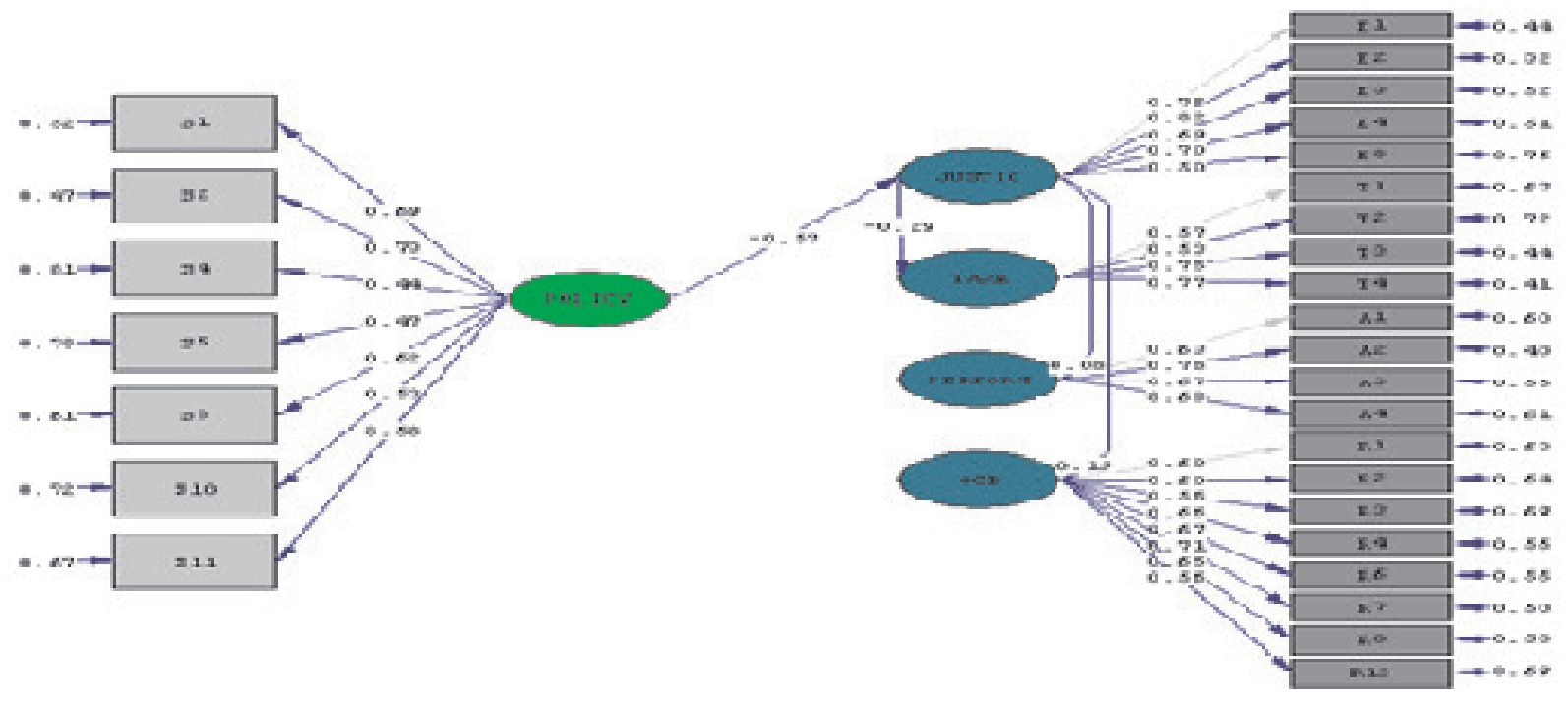




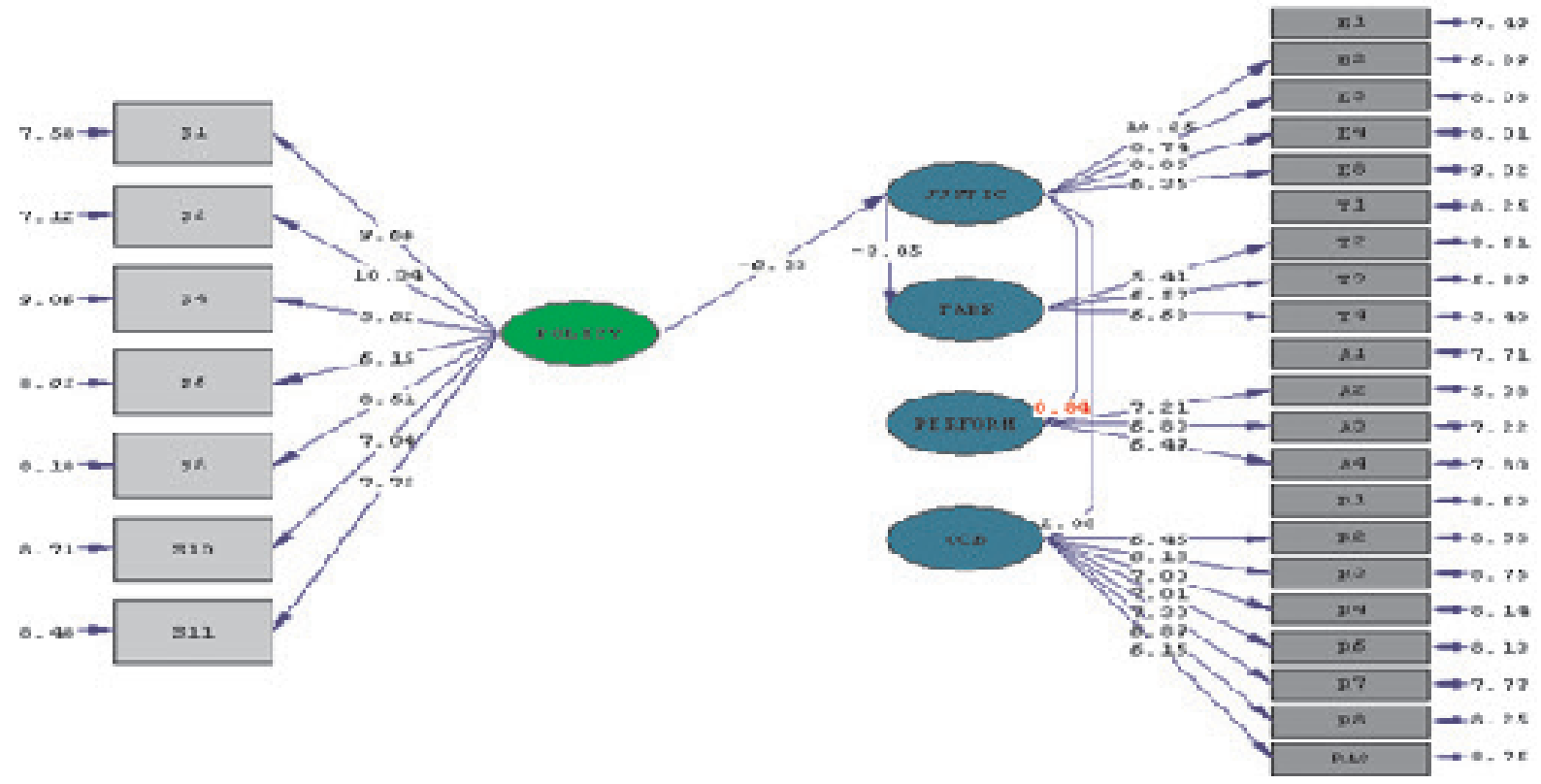

توانبخننى

بان NNFI بيان داشت الكوى نهايى از برازش خوبي برخوردار است.

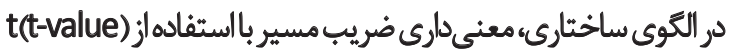

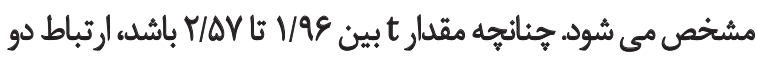

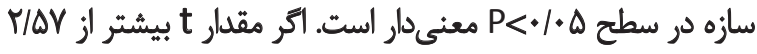

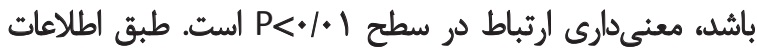

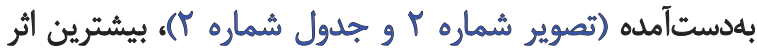

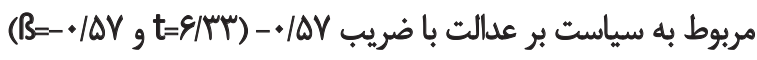

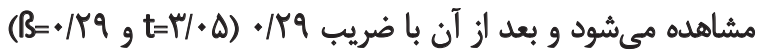
مربوط به اثر عدالت بر تمايل به ترك خدمث إن است

بحث

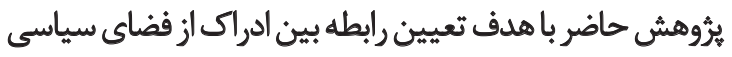
سازمان با تمايل به ترك شغلى، عملكرد شغلى و رفتار شهروندى رينى
برايناساس نتايج حاصل از تحليل الكوى ساختارى در جدول

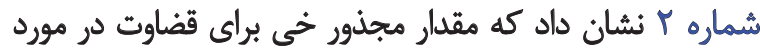

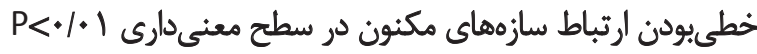

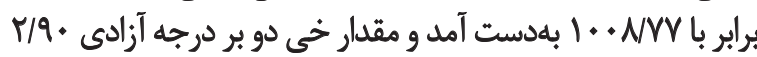

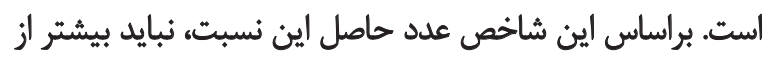

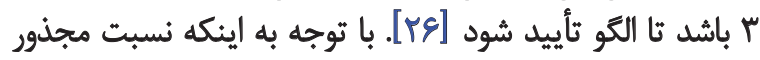

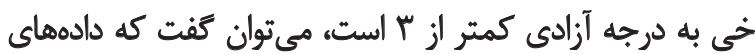

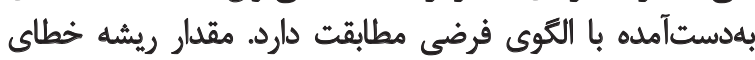

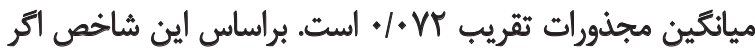

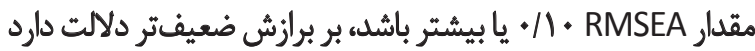

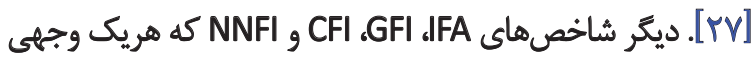

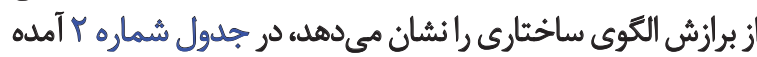

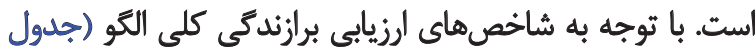

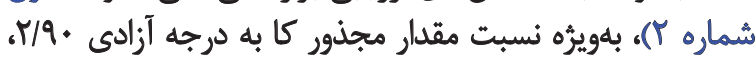

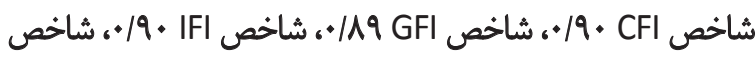

جدول "ا. ضرايب تأثير متغيرهاى مكنون با نقش ميانجى عدالت.

\begin{tabular}{|c|c|c|c|}
\hline نتيجي & $\mathbf{T}$ & ضريب مسير استأدارد & مسير فرضيهها \\
\hline اثر مستقيم دارد & $-8 / \pi$ &.$- / \Delta V$ & سياست عدالت \\
\hline اثر مستقيه دارد & $-r /+\Delta$ &.$- / 79$ & علالت ترى خلمت \\
\hline اثر مستقيه ندارد & ./AF & $\% 1$ & عدالث عملكرد \\
\hline اثر مستقيم دارد & $Y / \bullet A$ & .119 & عدالت رفتار شهروندى \\
\hline اثي غيرمستقيهم دارد & - & $-* / 1 Y$ & سياست ترك خدمت (الز طريق عدالت) \\
\hline اثر غيرمستقيم دارد & - & - & سياست عملكرد (از طريق عدالت) \\
\hline اثرغير مستقيم دارد & - &.$- / 11$ & سياست رفتار شهروثدى (از طريق عدالث) \\
\hline
\end{tabular}




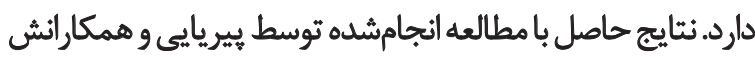

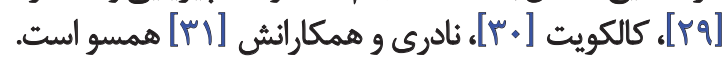

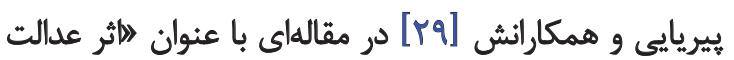

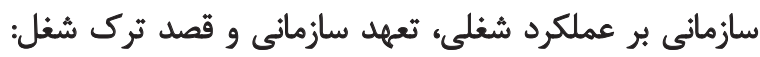

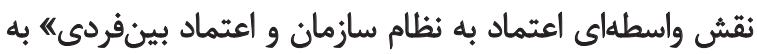

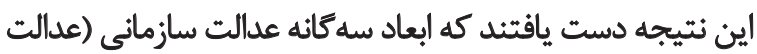

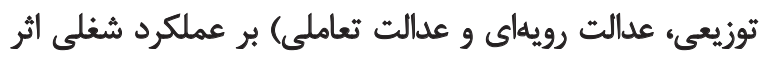

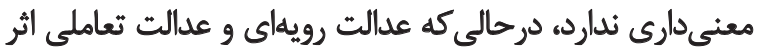

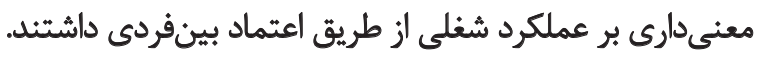

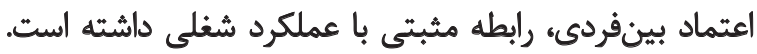

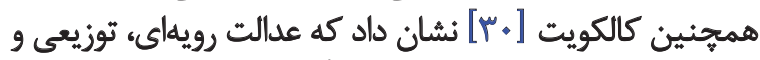

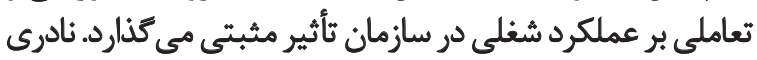

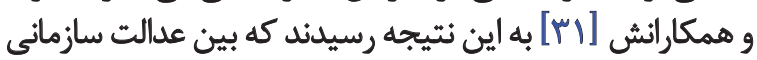

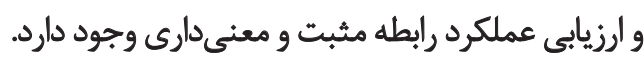

بين احساس عدالت سازمانى كاركنان و رفتار شهروندى دانى

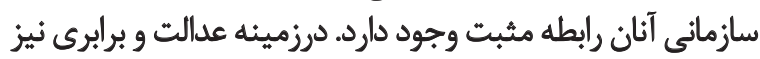

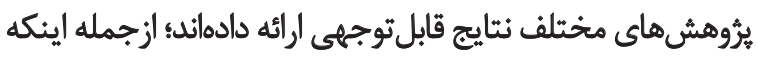

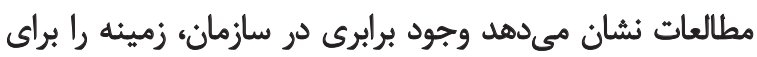

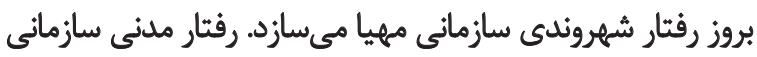

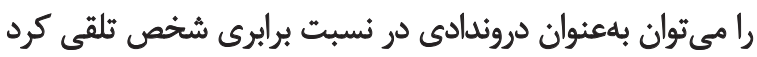

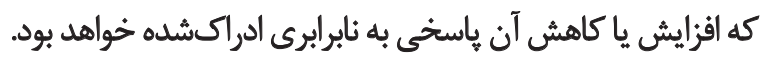

برهميناساس، اوركان بيان كرد ادراك انصاف در افزايش رفتارهاي

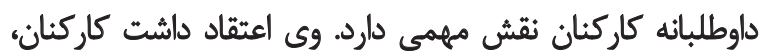

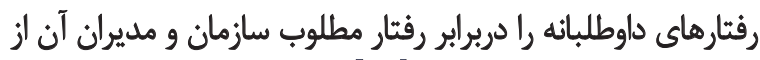

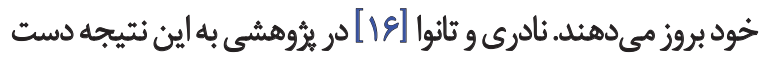

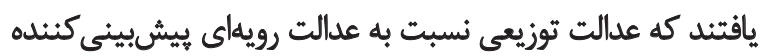

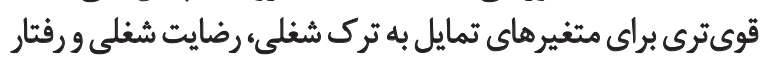

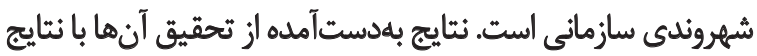

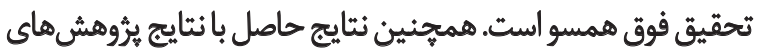

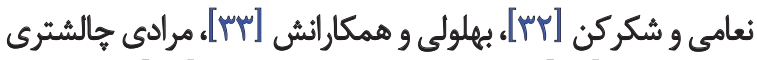

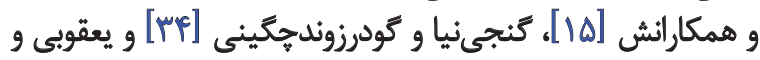
همكارانش [هّار] همسو است.

با توجه به يافتهها، عدالت سازمانى نقش ميانجى رادر رابطه بين

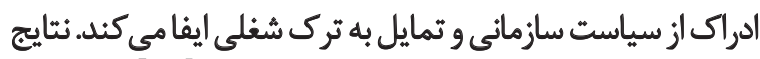

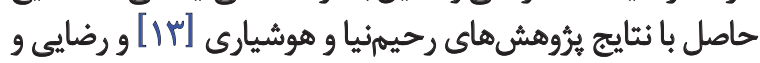

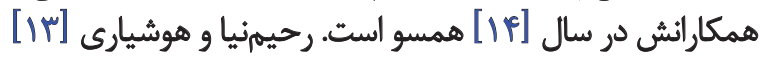

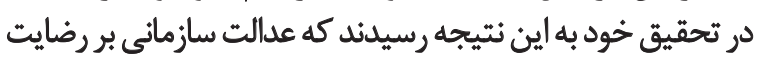

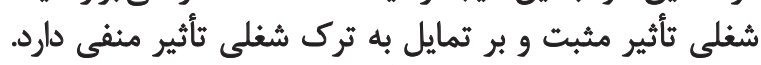

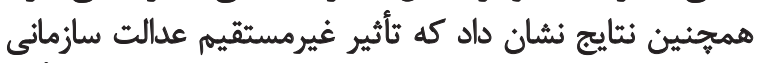

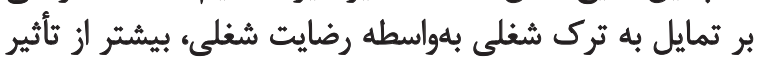

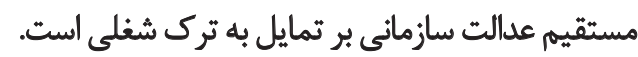

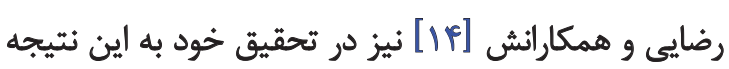

سازمانى با آزمون نقش ميانجى عدالت سازمانى درميان كاركنان

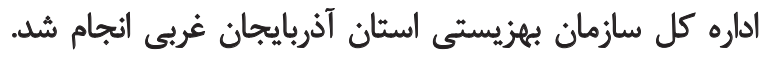

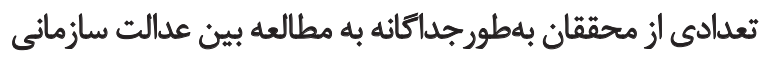

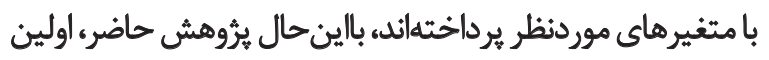

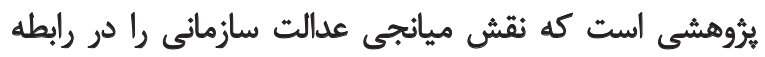

سياست سازمانى با تمايل به تركى شغلى ويانى عدا.. بررسى مئى كند.

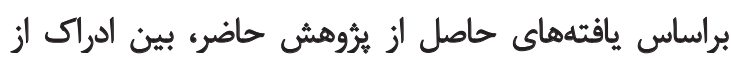

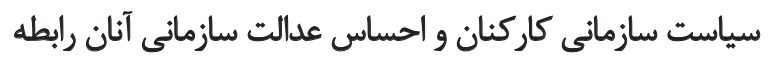

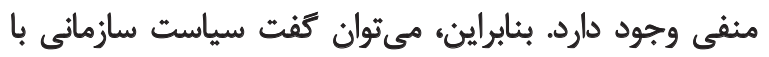

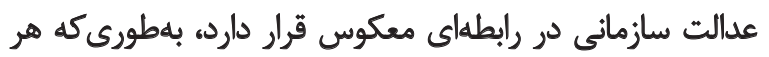

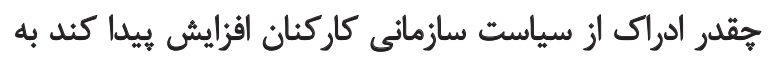

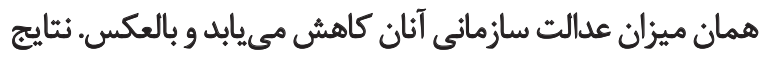

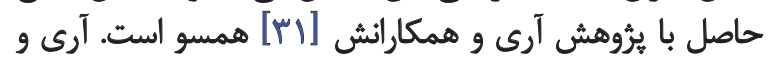

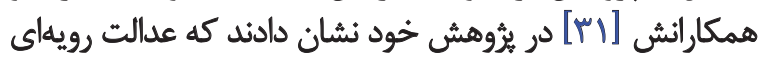

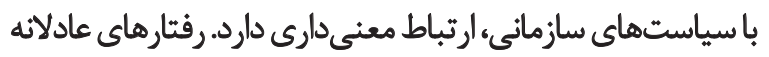

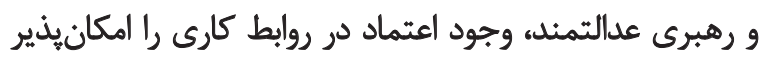

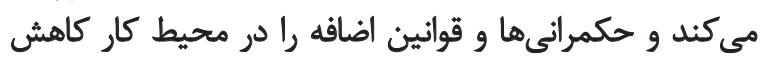

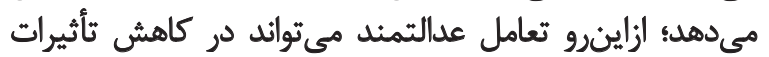
منفى سياست مهم باشد.

با توجه به يافتهها بين احساس عدالت سازمانى كاركنان و ميزان

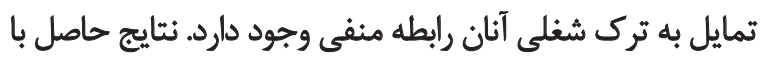

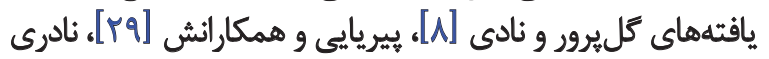

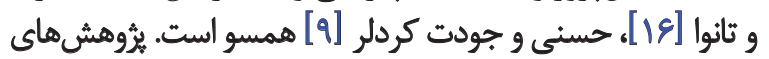

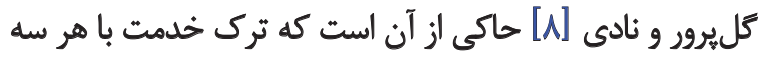
بُعد عدالت توزيعى، رويهاى و تعاملى داراى رابن رابطه منفى است.

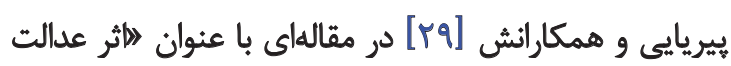

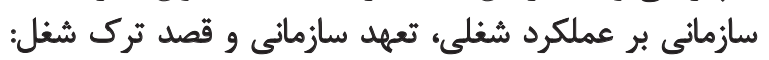

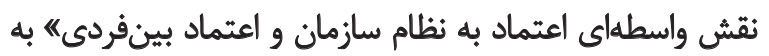

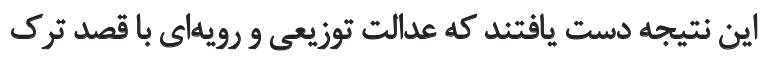

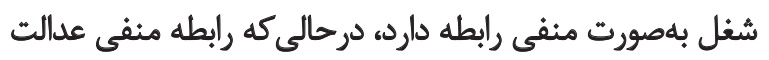

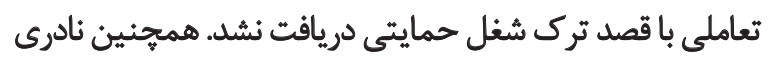

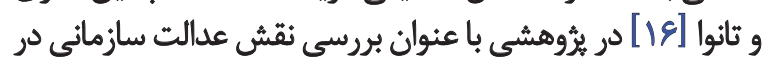

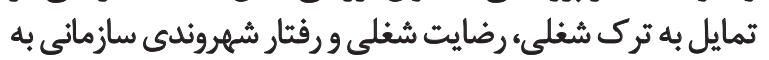

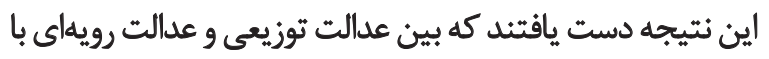
تمايل به ترى خدمت رابطه معنادارى وجود دارد. حسنى و جودت كردلر [9] در تحقيقى با عنوان "رابطه بين

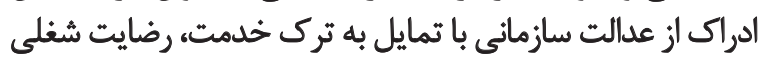

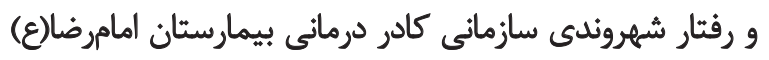

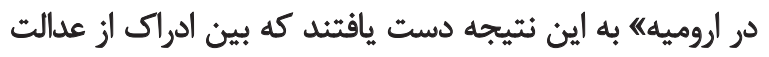

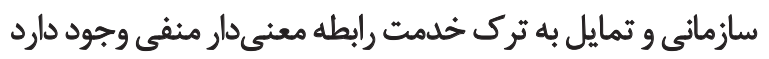

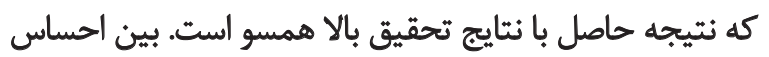

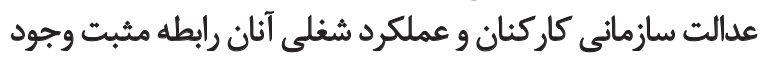


دراينراستا، برخى موضوعات در هيهارجوب اين مقاله براى تحقيقات آتى قابل ششناسايى است.

يشئنهادها

زيشنهادهاى زير ميتواند بر غناي تحقيقات بعدى در اين

زمينه بياقزايد:

• اكرجه در يثوهش حاضر به سطوح و ابعاد عدالت سازمانى

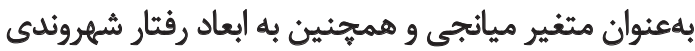

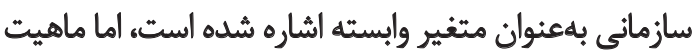
جندسطحى آنها در تحليل دادهها موردتوجه قرار بار نكرفتئه

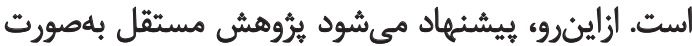

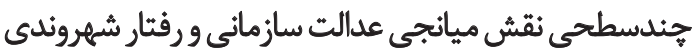
با متغيرهاى موردنظر را موردبررسى قرار دهائ

• استفاده از متغير ميانجى ديكُرى بهجاى عدالت سازمانى

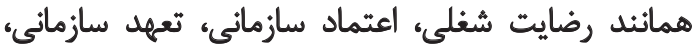

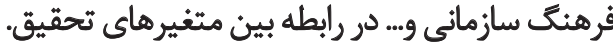
• بهدليل كمبود تحقيقات درزمينه سياست سازمانى، مى توان

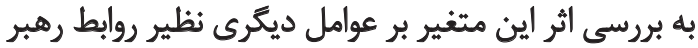
و بيرو، تنيدگى شغلى و جوّ اخلاقى سازمان و... برداخت

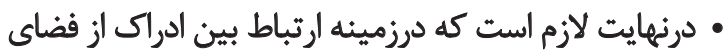

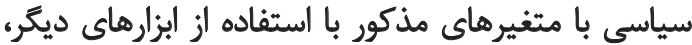
ئروهشهاى بيشترى صورت كيرد.

$$
\text { تشكر و قدردانى }
$$

بدينوسيله از همكاري مسئولين اداره كل سازمان بهزيستى استان

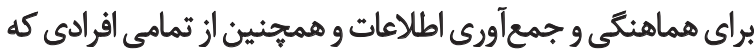

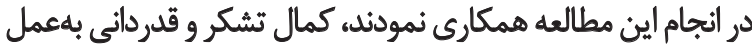

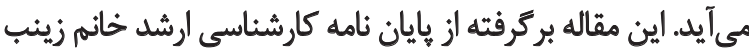

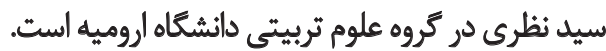

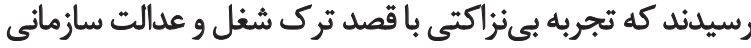

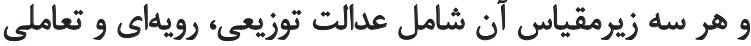

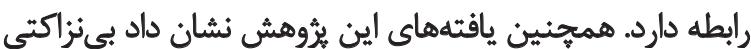

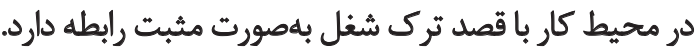

عدالت، نقش ميانجى را در رابطه بين سياست و عملكرد شغلى ايفا

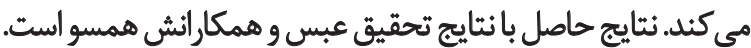

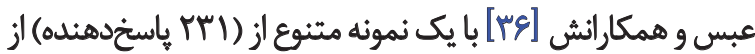

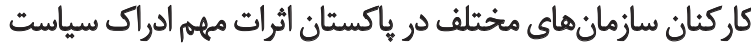

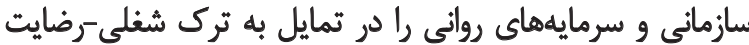

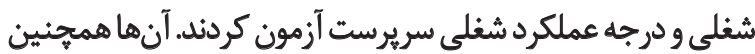

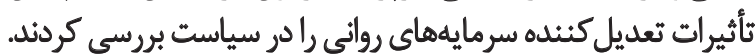

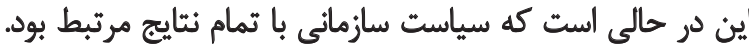

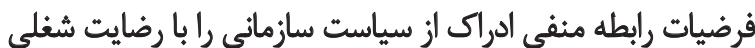

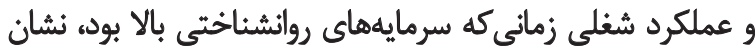

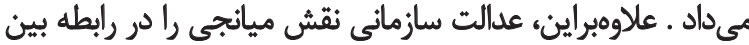

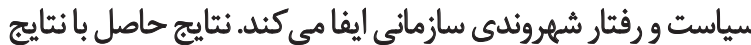
تحقيق رحيمنيا و حسنزاده [rV] همسو استئ.

\section{تتيجليرى}

براساس نتايج اين مطالعه مىتوان نتيجه كرفت كه عدالت

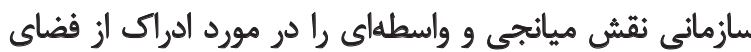

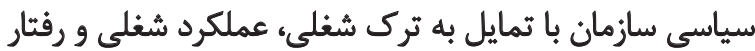

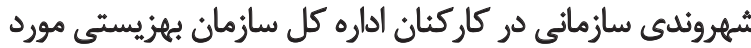

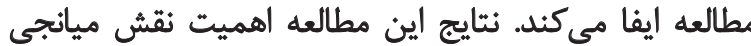

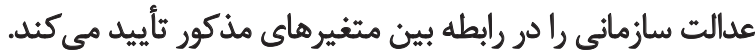

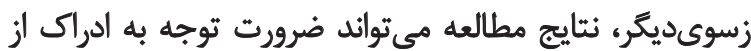

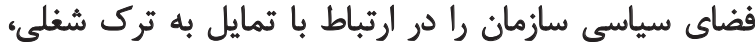

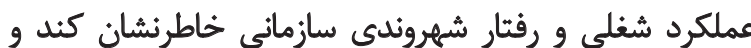

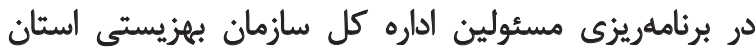

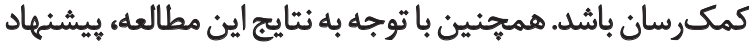

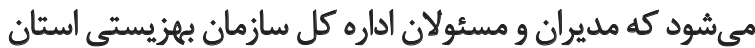

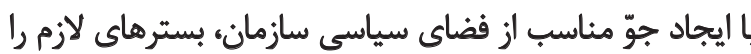

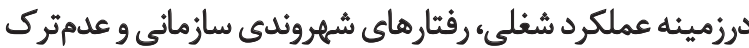

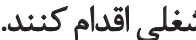

محدوديتها

از محدوديتهاي اين بيروهش همتتوان به عدمهمكارى

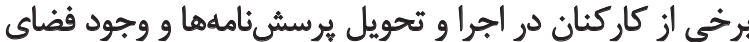

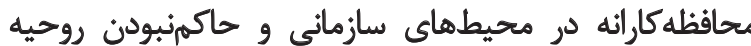

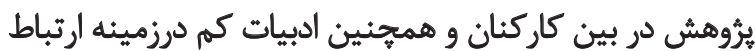

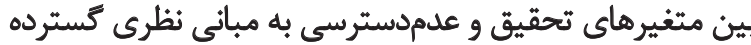

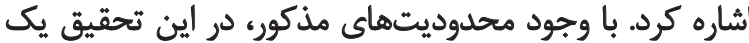

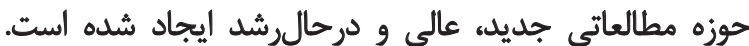




\section{References}

[1] Haghighi MA, Ahmadi A, Raminmehr H. [The effect of organizational justice on employee performance (Persian)]. Journal of Organizational Culture Management. 2010; 7(2):79-101.

[2] Cole ND, Flint DH. Perceptions of distributive and procedural justice in employee benefits: flexible versus traditional benefit plans. Journal of Managerial Psychology. 2004; 19(1):19-40. doi: 10.1108/02683940410520646

[3] Nori A, Sabahi P, Salahian A, Samim R. [The relationship between job satisfaction and perceived organizational justice with organizational citizenship behavior (Persian)]. Journal of Contemporary Psychology. 2013; 7(1):49-60.

[4] Nazem F, Hadadpour A. [The structural model of organizational justice on the basis of transformational leadership styles and pragmatic Islamic Azad University (Persian)]. Journal of New Approaches in Educational Administration. 2013; 4(51):1-66.

[5] Alizadeh A. [Factors affecting staff leaving job (Persian)]. Journal of Police Human Development. 2007; 4(11):74-89.

[6] Leow KL, Kok WK. Organizational Commitment: the study of organizational justice and leader member exchange (LMX) among auditors in Malaysia. International Journal of Business and Information. 2009; 4(2):161-198.

[7] Parhizkari M, Nikbakhsh R, Saboonchi R. Relationship between understanding of organizational justice and organizational citizenship behavior of Tehran physical education teachers. Researcher in Sport Science. 2010; 1(1):19-28.

[8] Golparvar M, Nadi M. [Cultural values and fairness: organizational justice, job satisfaction and turnover (Persian)]. Journal of Cultural Research. 2011;3(1):207-28.

[9] Hassani M, Jodatkordlar L. [The relationship between perceived organizational justice and turnover intentions, job satisfaction and organizational citizenship behavior hospital medical staff of Imam Reza (AS) Urmia (Persian)]. Bimonthly Journal of Urmia Nursing \& Midwifery Faculty. 2013; 10(3):340-52.

[10] Robinson K. The impact of individual differences on the relationship between employee perceptions of organizational justice and organizational outcome variables. [PhD dissertation] San Diego: Alliant International University; 2004.

[11] Barati H, Arizi HR, Nori A. [Relationships of Simple and multiple between organizational justice and job performance in Esfahan Steel Company (Persian)]. Journal of Management Perspectives. 2010; 33:9-28.

[12] Alper E. Increasing organizational citizenship behavior of Turkish academicians: mediating role of trust in supervisor on the relationship between organizational justice and citizenship behaviors. Journal of Managerial Psychology. 2007; 22(3):257-70. doi: $10.1108 / 02683940710733089$

[13] Rahimnia F, Hoshyar V. [The impact of organizational justice tend to leave the job through job satisfaction (Persian)]. Modiriate Farda Journal. 2011; 9(24):23-42.

[14] Rezayi F, Nori A, Arizi HR. [Workplace incivility and turnover intention: The mediating role of organizational justice (Persian)]. Knowledge \& Research in Applied Psychology. 2012; 12(4):40-50.
[15] Moradi Chaleshtari MJ, Jafari A. [Relationship between organizational justice and organizational citizenship behavior staff in Physical Education Organization of Islamic Republic of Iran (Persian)]. Olympic Journal. 2012; 53(1):145-156.

[16] Nadiri H, Tanova C. An investigation of Justice, in turnover intentions, Job satisfaction and organization citizenship behavior in hospitality industry. International. Journal of Hospitality Management. 2010; 29(1):33-41. doi: 10.1016/j.ijhm.2009.05.001

[17] Mosakhani M, Alvani M, Mirzayi M, Mohammadi S. [The relationship between organizational citizenship behavior and employee performance (Persian)]. Journal of Management. 2013; 9(25):75-90.

[18] Jorbonian A, Makarem A, Hosseini MA, Bakhshi E. [The relatonship between organizational citizenship behavior and organizational commitment in welfare staff, Tehran 2013 (Persian)] Journal of Rehabilitation. 2014; 16(1):18-25.

[19] Shayanjahromi SH, Salehi M, Imani J. [Relationship between organizational justice and organizational commitment and job satisfaction among teachers of special schools city of Bandar Abbas (Persian)]. Journal of Education. 2010; 2(5):7-33.

[20] Vigoda E. Stress-related aftermaths to workplace politics : the relationships among politics, job distress, and aggressive behavior in organizations. Journal of Organizational Behavior. 2002; 23(5):571-91.

[21] Niehoff BP, Moorman RH. Justice as a mediator of the relationship between methods of monitoring and Organizational citizenship behavior. Academy of Management Journal. 1993; 36(3):527-56. doi 10.2307/256591

[22] Kacmar KM, Carlson DS. Further validation of the perceptions of organizational politics scale (POPS): a multiple sample investigation. Journal of Management. 1997; 23(5):627-58. doi: 10.1177/014920639702300502

[23] Miller H, Katerberg R, Hulin C. Evaluation of the Mobley, Horner and Hollingsworth model of turnover. Journal of Applied Psychology. 1979; 64(5):509-17. doi: 10.1037/0021-9010.64.5.509

[24] Williams LJ, Anderson SE. Job satisfaction and organizational Commitment as predictors of organizational citizenship and in - role behavior. Journal of Management. 1991; 17(3):601-17. doi: $10.1177 / 014920639101700305$

[25] Podsakoff P M, Mackenzie SB, Beth Pain J, Bachrach DG. Organizational citizenship behavior: a critical review of the theoretical and empirical literature and suggestions for future research. Journal of Management. 2000; 26(3):513-63. doi $10.1177 / 014920630002600307$

[26] Klein P. [Easy guide factor analysis (SJ. Sadrossadat, Persian trans)]. Tehran: Samt Publication; 2013.

[27] Hooman HA. [Structural equation modeling using LISREL software. Tehran (Persian)]. Tehran: Samt Publication; 2005.

[28] Aryee S, Xiong CZ, Budhwar PS. Exchange fairness and employee performance B:An examination of the relationship between organizational politics and procedural justice. Journal of Organizational Behavior and Human Decision Processes. 2004; 94(1):1-14. doi 10.1016/j.obhdp.2004.03.002 
[29] Piriaei S, Arshadi N, Nisi A. [The effect of organizational justice on job performance, organizational commitment and turnover intention: the mediating role of trust in the organization and interpersonal trust (Persian)]. Journal of Psychological Achievements. 2014; 4(3):96-92.

[30] Colquitt JA. On the dimensionality of organizational justice A construct validity of a measure. Journal of Applied Psychology. 2006; 86(3):386-400. doi: 10.1037/0021-9010.86.3.386

[31] Naderi N, Hoveyda R, Syadat A. [The relationship between organizational justice component of employee performance evaluation Esfahan Oil Refining Co. (Persian)]. New Approaches to Training. 2011; 2(12):97-112.

[32] Naami A, Shekarkan H. [Examine the relationship between organizational justice and organizational citizenship behavior of employees in the industrial city of Ahvaz (Persian)]. Journal of Education \& Psychology. 2007; 3(1):79-92.

[33] Bohlooli Z, Alavi M, Derakhshanmehrabani AS. [The effect of organizational justice, organizational citizenship behavior, Islamic Azad University of Tabriz (Persian)]. Journal of Beyond Management. 2011; 4(14):73-108.

[34] Ganjinya H, Godarzvandchegini M, Ghaffarzadeh A. [The effect of perceived organizational justice and organizational citizenship behavior (Persian)]. Management Studies in Development and Evolution. 2011; 20(61):91-120.

[35] Yaghoubi M, Yarmohammadian M, Raeisi A, Javadi M, Saghaiannejad S. [The Relationship between the organizational justice and organizational citizenship behavior among medical records staffs of selected hospitals of Isfahan (Persian)]. Health Information Management. 2011; 7(1):506-15.

[36] Abbas M, Raja U, Darr W, Bouckenooghe D. Combined effects of perceived politics and psychological capital on job satisfaction, turnover intentions, and performance. Journal of Management. 2012. doi: $10.1177 / 0149206312455243$.

[37] Rahimnia F, Hassanzadeh J. [The moderating role of organizational justice on perception of organization politics and communication apprehension (Persian)]. Transformation Management Journal. 2010; 1(2):21-46. 
